\title{
Determining the role of energy consumption and air pollution on Pakistan's economic growth: Application of Autoregressive Distributive Lag Model (ARDL)
}

\author{
Baseerat Sultana', Abdul Mansoor ${ }^{2^{*}}$ \\ 1,2Lecturer Economics, University of Wah, Wah Cantt, Pakistan \\ *Corresponding Author email: abdul.mansoor@uow.edu.pk
}

Submission: 20 July 2020

Revised: 24 August 2020

Accepted: 19 September 2020

\begin{abstract}
Goals of this study are to observe the impact of energy consumption, $\mathrm{CO}_{2}$ emission on Pakistan's economic growth by using annual time series data from 1980 to 2016. Autoregressive lag distributive (ARDL) model is applied to find out the correlation between variables. The short-run elasticity shows that $\mathrm{CO}_{2}$ emission, fossil fuel, and hydro energy consumption decrease Pakistan's economic growth. In contrast, nuclear energy consumption and electric power consumption substantially increase Gross domestic product (GDP) per capita of the country. In the long run, nuclear energy consumption and electric power generation support the country's economic growth, which needs more environmental friendly policies to reduce high mass carbon emissions in a country.
\end{abstract}

Keywords: $\mathrm{CO}_{2}$ Emission, Energy Consumption, Economic Growth

\section{INTRODUCTION}

Human activities regarding the consumption of energy are one of the main factors that leave a deep impact on the climatic changes in the ecosystem and global warming problems. Global warming is an alarming phenomenon that deeply concerns about limited energy sources on one side and the green energy paradigm on another. The causal relationship among energy consumption, hazard gases emission, and sustainable growth of the economy has been extensively debated over the recent decades (Stern, 2004). Energy plays a major part in social welfare but on the other hand, it affects welfare in terms of socio-economics and environmental degradation that is directly connected to the different energy consumption resources. For instance, the higher the economic growth, the higher the energy consumption will lead to an increase in $\mathrm{CO}_{2}$ emissions that cause environmental degradation. South Asian region is undergoing a rapid economic as well as population growth along with high dependency on energy consumption and hence pollution emission. So, attaining a high pace of development and changing living standards resulted in polluted environment and hazardous gas emission (Chontanawat, 2020). The renewable energy consumption not only fulfills the energy demand of the nation but also save the environment from degradation (Gralla et al., 2017). As in the Middle East and North Africa (MENA) region countries (Egypt, Algeria, Bahrain, Iran, Iraq, 
Israel, Jordan, Kuwait, Lebanon, Libya, Morocco, Oman, Qatar, Saudi Arabia, State of Palestine, Syrian Arab Republic, Tunisia, UAE, Yemen), the use of renewable energy plays a vital role to fulfill the demand for energy. But the use of these inputs for generating electricity remains low however, some countries take a critical step in the recent past. In this regard, the share of Turkey is high to energy through the renewable process by adopting renewable resources. Turkey produced only $28.8 \%$ of the total energy from the renewable resource in 2013 (World development indicator, 2016). To produced energy from renewable resources, hydropower is the cheapest source to produce. On the ground of non-hydro energy consumption, Morocco is the $1^{\text {st }}$ country in the MENA region that passed the 5\% threshold ratio to produced energy from the non-hydro resources. The requirement of non-renewable induces the demand to produce the energy but on the contrary, it reduces the environment quality by the emission of $\mathrm{CO}_{2}$.

In the recent years, electricity production in Pakistan by using fossil fuels is $66.0 \%$ but the contribution of fossil fuels in energy production has persisted in the past few years as it shares in 2005 is 66.5\% (World energy outlook, 2017). International energy agency in 2017 published a report that's aim is sustainable development and the provision of clean and reliable energy without any emission of $\mathrm{CO}_{2}$. According to the report, the share of nuclear energy consumption will become twice in 2040 as it increases by 5345 terawatts and its capacity to grow is 720 gaga watts. The whole world is involved in alternative nuclear power development. As Canada operates 19 nuclear reactors with a net capacity of 13.5 gaga watts and the USA operates 99 nuclear reactors and its net capacity is 99.6 gaga watts, about $20 \%$ of USA energy demand was fulfilled by the nuclear source in 2016. In Germany 7 nuclear power reactors are working and its net capacity was 9.4 gaga watts. However, $13 \%$ of electricity is produced through the nuclear process. India has 22 operable nuclear reactors and its capacity is 6.2 gaga watts that fulfill the $3 \%$ energy demand of India. Pakistan has 5 nuclear reactors with a capacity of 1.4 gaga watts, although $4 \%$ of the electricity is produced by the nuclear process in 2016 (World nuclear association, 2018).

Understanding the importance of energy in economic growth, Pakistan also struggles to increase the source of energy production at the domestic level. Pakistan's economy already faces energy crises that adversely affect the growth of the economy. Due to load shading, the gap between demand and supply, energy insecurity, and dependency on debt and imports increase. In line with this crisis, it is documented that over 100 billion \$ cost is paid by the Pakistan economy. The impact of the energy crisis on the industrial sector is that many production units in the major cities of Pakistan have shut down or they operate at the minimum level (Kugelman, 2015). In 2016 the average shortfall of the energy sector was 4000 megawatts. This shortfall rises to 7000 megawatts or 32/P of total demand for electricity. Due to this shortfall, over 140 million Pakistani do not have access to power generation or suffer 12 hours of load shading. It is also observed that the demand for electricity consumption for household increase $10 \%$ points on average on annual basis. This energy deficit also boosts the unemployment ratio that adversely affects the business. To overcome this shortage government of Pakistan tried to increase the power capacity. In this ground first, that is taken by the government is the effective 
use of energy as about $67 \mathrm{Pc}$ of domestic energy consumption are use ineffective in the form of lights and fans. Load shedding was reduced by $39 \%$ due to the efficient use of fans and $47 \%$ due to the efficient use of lights. Another source of renewable energy consumption is the wind, solar, water, and nuclear energy. At present time, The China Pakistan economic corridor project planned to add up $200 \mathrm{MW}$ wind energy and $1000 \mathrm{MW}$ solar energy (Kazmi et al., 2016). In the respect of nuclear energy consumption Pakistan take some steps in August 2011. On the advice of the Pakistan nuclear regulatory authority (PNRA) and international energy agency, Pakistan Atomic energy communication (PAEC) has selected six sides. For this purpose, Qadir Abad; Bulloki link cannel near Qadiraba. Dera Ghazi Khan Canal near Taunsa Barrage, Taunsa-Panjnad cannel Multan; Nara canal near Sakkur; Pat Feeder canal Guddu and Kabul river near Nowshera. While in 2012 PAEC plan to place 4 more unclear segments in Multan on Taunsa- panjnat. In 2014 PAEC proclaimed to build furthermore plants that capacity is $1100 \mathrm{MW}$ that fulfill the access energy demand. In CPEC 8 more places are chosen for more 32 units (World nuclear association, 2018).

Hydro is an another renewable source of producing energy. In Pakistan, $42 \%$ of energy is produced through the water. The cost of the hydropower projects is very high but the cost of energy production is relatively low. In Pakistan Tarbela, Mangla, and Warsak dams are working. Tarbela is the largest project of hydroelectricity that was built on the Indus River in 1976. Mangla dam is constructed on the River Jhelum in 1967, while the Warsak dam is constructed on the River Kabul in 1960. The hydropower plant plays its vital role to overcome the power lack. According to the estimation of some studies, the electricity generation from hydro sources will increase by more than $40 \%$ in 2030. Many hydropower plants are completed in the Khyber Pakhtunkhwa such as Ronolia (17MW), Dara Khar (37MW), Machai (2.6 MW) in 2016. To increase the electric capacity of the dam's water and power development authority (WAPDA) starts some projects in the recent year. However, the fourth extension of 3,478 megawatts Tarbela hydro plants is completed in 2017 and now the net capacity is 4,888MW. To plant the fifth extension the World Bank and Asian infrastructure investment Bank decided to provide the 720 million USD. This fifth extension will increase the 1,140 megawatts installing capacity (World energy council, 2017).

This paper will highlight the effect of energy consumption and $\mathrm{CO}_{2}$ emission on economic growth. This study employs a new technique that is the autoregressive lag distribution model (ARDL) or vendor error correction model (VECM). The importance of ARDL is that it handles both the I (0) and I (1) processes that gives the robust result. It also shows the long- and short-term association among the variables, and VECM shows the convergence and divergence towards the equilibrium. In the case of disequilibrium if the government adopts any policy then the economy moves toward stability or disability. It also tells how much time is required to stabilize the economy that's why this study employs the ARDL and VECM. 


\subsection{RESEARCH GAP:}

Many studies worked out on the different energy consumption and growth specific factors however very few studies check the influences of renewable energy uses across different growth settings. The use of nuclear energy and its impact on growth specific factors is analyzed in the energy resource framework. This paper is one of the key initiatives to check the role of nuclear energy consumption on Pakistan's economic growth.

\subsection{OBJECTIVES}

Study objectives are:

1. To observe the effect of nuclear energy consumption on Pakistan's growth matrix.

2. To analyze the influence of environmental resource factors on Pakistan's economic growth.

3. To examine the influences of hydro and electric power consumption on Pakistan's economic growth.

\section{LITERATURE REVIEW:}

Many studies are conducted on energy use and its impact on the growth and environment. All studies show some effects on countries' economic growth. Salahuddin et al. (2018) study on the relationship between the energy use, environmental quality, and growth in Kuwait and finding of the study shows energy use and economic growth both affect the environmental quality and there is a strong association of GDP and energy use with the $\mathrm{CO}_{2}$ emission. Xie et al. (2018) checked the relationship between renewable energy consumption and $\mathrm{CO}_{2}$ emission. To examine the correlation, they select the most pollutant areas of china Jing-Jin-Ji regions and the result shows that the renewable energy consumption helps to reduce the $\mathrm{CO}_{2}$ emission according to this study $21 \%$, 31\%, and $28 \% \mathrm{CO}_{2}$ emission in Beijing Tianjin and Hebei in coming years. Policies that are designed in Hebei on the adaptation of renewable energy consumption would be affected to decrease the $\mathrm{CO}_{2}$ emission. Rafindadi et al. (2018) studied energy use and environmental quality in the gulf cooperation council (GCC) countries, and the finding of the study shows that clean electric consumption significantly improves environmental quality. Bekhet et al. (2017) studied about the energy use, GDP, and emission of $\mathrm{CO}_{2}$ in GCC countries, and confirmed unidirectional association among the energy use and emission of $\mathrm{CO}_{2}$ in the case of UAE, Saudi Arabia, and Qatar. Al- Maamary et al. (2017) checked the impact of natural resource prices on energy consumption in GCC countries. The study of Zaman (2020) suggests channelizing the material technology to achieve sustainable development by adopting green material technologies. Some studies documented some contrasting outcomes regarding renewable energy consumption and environmental degradation in the countries like China, the USA, Canada, Brazil, and Germany while they found this relationship in line with the study of Zaman (2020) in the countries like India, Russia, and Indonesia. Their results indicate the adoption of advanced technology and the environment-friendly mechanism that is adopted in countries like 
China and US as compared to the traditional production approaches in the developing nations. These results are in line with the outcomes of Dabachi et al. (2020) and Usman et al. (2020) suggesting high tax imposition of non-renewable energy that will enhance the potential in clean energy and improvement of environmental quality of a country. This study shows if the price of natural resource energy consumption increases it would transform the use of energy to the alternative method. It is also observed that in GCC countries, growth in energy consumption is much faster than the economic growth and in 2008 the state of GCC adopts sustainable policies such as resources efficiency programmer's clean technology renewable energy consumption grow plants and so on, but these policies are not although implemented and still on the paper. If these policies are adopted, it would enhance economic growth without harming the ecosystem. Shahbaz et al. (2017) studied the energy use and economic growth of 157 countries and apply panel co-integration and pool mean group test to show the unidirectional causality between energy consumption and economic growth in the short and long run. Dai et al. (2016) documented the influence of large-scale alternative energy growth in China. Their Study incircles the two aspects, one is the development in the alternative energy use and renewable energy max and the study shows that in 2050 if primary energy achieves the $56 \%$ share then its contribution in GDP is $3.4 \%$ and other sectors contribution are $2.5 \%$ agriculture $3.3 \%$ iron and steel and $2.1 \%$ of construction. The other aspect is RE max this shows that development in RE on large scale would help to increase the output of 1.18trillion from other RE-related industries and it also created 4.12 million jobs in 2050 so it also helps to reduce the $\mathrm{CO}_{2}$ emission and other pollutants. Zaman et al. (2017) checked the association between energy consumption and air pollution in Pakistan. The result shows a significant positive correlation between energy consumption and air pollution in the long and short run. Tang et al. (2016) investigated Vietnam's energy use and growth factor, finding of the study show that energy consumption significantly increases the GDP of Vietnam. Inglesi- Lotz (2016) has also established that renewable energy is the only thing that not only promotes the growth of the economy but also saves the environment from degradation. Zaman et al. (2017) suggested that the increase in the energy demand would increase the demand for natural resources and the finding of the ganger causality shows a bidirectional causality relationship the energy consumption and natural resource depletion, $\mathrm{CO}_{2}$ emission. Tang and Tan (2015) find a bidirectional relationship between economic growth and $\mathrm{CO}_{2}$ emissions in Vietnam. Cheng et al. (2015) also examined the Carbon trading scheme on emissions and for this purpose, they select the China province Guangdong and the result of the computable general equilibrium (CGE) model show that the carbon ETS helps to reduce the emission by $12.4 \%$ to $11.7 \%$ in 2020 . If the ETS policy is adopted, then it would help to exchange the 38,000 tons of air pollution into carbon trading sectors that are valued at 50 million US \$. Alshehry and Belloumi (2015) studied the energy use environmental degradation and economic growth in Saudi Arabia and result shows in long-run bidirectional correlation exist among the energy use economic growths and $\mathrm{CO}_{2}$ emission, or between $\mathrm{CO}_{2}$ emission and GDP is bidirectional association exists. However, in the short-run unidirectional relationship exist between $\mathrm{CO}_{2}$ emissions and energy consumption, and economic growth. Their study suggests that there must be a need in Saudi's economy to increases the renewable energy sources and reducing fossil 
fuel consumption that helps to reduce the $\mathrm{CO}_{2}$ emissions. Bloch et al. (2015) confirms that non-renewable energy sources degrade the environment and would also result in a significant increase in $\mathrm{CO}_{2}$ emissions. Apergis et al. (2010) found a negative relationship between $\mathrm{CO}_{2}$ emissions and clean energy use, the result of the panel granger casualty test shows that in the long-run increase in nuclear energy consumption reduces the emission level. Rufael and Menyan (2010) suggested that in Spain, the United Kingdom, and the USA due to an increase in nuclear energy consumption would increase GDP.

\subsection{DATA AND VARIABLES:}

This paper uses time-series data from 1980 to 2016 to examine the relationship between energy consumption, air quality, and growth in Pakistan. This study includes nuclear energy (\% of total energy use), fossil fuel energy consumption (\% of total), $\mathrm{CO}_{2}$ emissions (metric tons per capita), GDP per capita (constant US\$), Electricity production from hydroelectric sources (\% of total) and Electric power consumption (kWh per capita) taken from the world development indicators Published by World Bank.

\section{METHODOLOGY:}

This study employs an Autoregressive distributive lag model (ARDL). ARDL is a dynamic regression tool based on standard least squares regression that involves the lags of dependent and independent variables. ARDL model provides robust estimates of variables as it analyses the data in the short run and long run. Moreover, ARDL also provides the per annum convergence rate of an economy if there is an external shock (Pesaran et al., 2001). We are interested in the short and long-run dynamics of the economy, therefore, ARDL is the more appropriate model in this regard. ARDL models have some prerequisite tests of a unit root.

ARDL model is a special nature to accept those variables which are non-stationary at their $7^{\text {st }}$ differences. But it can not be applied to those data sets which are I(2). So the selected variables included in the model would be either I (0) and I (1) or a mix of both.

The economic analysis suggested the long-run relationship between variables due to constant means and variance. But sometimes means and variances change with time, so it would not give a satisfactory result. So, in this situation, ARDL co-integration and bond co-integration technique is applied. It also tells the long term and short-term association between the variables by using the F- statistics. If the significance of F- statistics is larger than the critical value of an upper bond, then it shows the long-run relationship among the variables or if the value is smaller than the critical value of a lower bond then the relationship between variables is short term. The advantage of ARDL is that it can handle multiple vectors. In the case of forecasting, it is necessary to follow the basic conditions of ARDL. If these conditions are not fellows then the model is misspecified and unrealistic with its implication on forecasting and policy (Nkoro and Uko, 2016)

\subsection{EMPIRICAL MODEL OF THE STUDY}

$$
G D P_{t}=\beta_{0}+\beta_{1} C O_{2 t}+\beta_{2} F F U L_{t}+\beta_{3} N E C_{t}+\beta_{4} H E C_{t}+\beta_{5} E P C_{t}+\varepsilon_{t}
$$


Where GDP shows the GDP per capita (constant 2010 US\$), NE shows the nuclear energy consumption (\%age of total energy use), FFUEL shows the fossil fuel energy consumption in \%age of total energy consumption, $\mathrm{CO}_{2}$ shows the carbon dioxide emission in metric tons per capita, HEC shows the Electricity production from hydroelectric sources (\% of the total, EPC shows the Electric power consumption (kWh per capita), Bo represent the intercept and $\varepsilon$ shows the error term.

\subsection{STATIONARITY TEST:}

ARDL can estimate variables which are I (0) and I (1) or both. Variables which are I (2) cannot be proceeded for ARDL estimations (Pesaran et al., 2001). To check the unit root, the Augmented Dickey-Fuller test (ADF) is applied. ADF test is based on the null hypothesis that data is stationary and against the alternative that data is non-stationary. ADF test includes negative numbers. If the value of $\mathrm{t}$-stat is negative, $\mathrm{H}_{\mathrm{O}}$ is rejected at any significant level of 1\%, 5\%, and 10\% (Chiang and lee, 2009).

$$
\Delta Y_{t}=\alpha+\beta_{t}+\gamma Y_{t-1}+\delta_{1} \Delta Y_{t-1}
$$

In equation $2 \alpha$ shows the intercept, $\beta$ shows the slope, $\mathrm{p}$ is the lag order by employing the restriction that is $\alpha=0$ and $\beta=1$ corresponding to the modeling of the random walk. Unit root also implies that $H_{0}$ is $\gamma=0$ and $H_{1}$ is $\gamma<0$. If the value of $t$-statistic

$$
D F_{T}=\gamma / S . E(r)
$$

Is calculated from the 3rd equation then compare with the critical value of Dickey-Fuller test. $\mathrm{H}_{\mathrm{O}}$ is rejected in that case when the value of the t-state is less than the critical value.

\subsection{SHORT RUN AND LONG RUN ESTIMATES:}

\subsubsection{Model:}

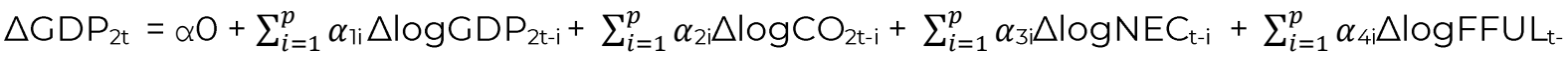

$$
\begin{aligned}
& \mathrm{i}+\sum_{i=1}^{p} \alpha_{5 i} \Delta \log \mathrm{NEC}_{\mathrm{t}-\mathrm{l}}+\sum_{i=1}^{p} \alpha_{6 i} \Delta \log \mathrm{EPC}_{\mathrm{t}-\mathrm{i}} \alpha+\lambda_{1} \log \operatorname{GDP}_{2 \mathrm{t}-\mathrm{i}}+\lambda_{2} \log \mathrm{CO}_{2 \mathrm{t}-\mathrm{i}}+\lambda_{3} \log \mathrm{NEC}_{\mathrm{t}-\mathrm{i}}+ \\
& \lambda_{4} \log F F U L_{t-i}+\lambda_{5} \log O R_{t-i}+\varepsilon_{t--}
\end{aligned}
$$

In equation $4 \Delta$ shows the first difference $\alpha_{0}$ shows the intercept, while $\varepsilon_{\mathrm{t}}$ shows the error term and $\mathrm{GDP}, \mathrm{CO}_{2}, \mathrm{NEC}, \mathrm{FFUL}, \mathrm{HEC}$, and EPC are the variables that are explained above $\mathrm{a}_{\mathrm{i}}$ shows the coefficient of variables. Hence $\lambda$ represents the long-run association among the independent variables with the dependent variables. The model estimate $(p+1)^{k}$ amount of regressions to check the optimal lag length of every variable, $p$ shows the optimum lag length of $k^{\text {th }}$ variables that are used to estimate the equation. This lag length approach is based on the Schwarz Bayesian criterion (SBC) and Akaike information criterion (AIC). While the bound testing technique is constructed on the F-statistic and Wald statistic. $\mathrm{H}_{0}$ in this approach is that there is no long-run association between the variables. In the bound test approach if the significance of F-stat is great then the 1 bound then $\mathrm{H}_{\mathrm{O}}$ is rejected which means that there is a long term association between the variables and if the significance of F-statistic is smeller then the $\mathrm{O}$ bound then $\mathrm{HO}$ is accepted which 
means that there is no long-run correlation among variables, and if the significance lies between the 1 bound and $\mathrm{O}$ bound then results are unconvincing (Pesaran and Shin, 2001).

\subsubsection{Stability:}

After confirming the long-run association, the next step is to check the short-run adjustment of the external shocks in the economy that is the error correction model (ECM).

\subsubsection{Model:}

$\triangle \mathrm{GDP}_{2 \mathrm{t}}=\alpha_{0}+\sum_{i=1}^{p} \alpha_{1 i} \Delta \log \mathrm{GDP}_{2 \mathrm{t}-\mathrm{i}}+\sum_{i=1}^{p} \alpha_{2} \Delta \log \mathrm{CO}_{2 \mathrm{t}-\mathrm{i}}+\sum_{i=1}^{p} \alpha_{3 i} \Delta \log \mathrm{NEC}_{\mathrm{t}-\mathrm{i}}+\sum_{i=1}^{p} \alpha_{4 i} \Delta \log \mathrm{FFUL} \mathrm{L}_{\mathrm{t}-\mathrm{i}}$ $+\sum_{i=1}^{p} \alpha_{5 i} \Delta \log \mathrm{HEC}_{\mathrm{t}-\mathrm{i}}+\sum_{i=1}^{p} \alpha_{6 i} \Delta \log \mathrm{EPC}_{\mathrm{t}-\mathrm{i}}+\lambda_{7} \log \mathrm{GDP}_{2 \mathrm{t}-\mathrm{i}}+\lambda_{2} \log \mathrm{CO}_{2 \mathrm{t}-\mathrm{i}}+\lambda_{3} \log \mathrm{NEC}_{\mathrm{t}-\mathrm{i}}+\lambda_{4} \log \mathrm{FFUL}_{\mathrm{t}-\mathrm{I}}$

$$
+\lambda_{5} \log H E C_{t-1}+\lambda_{6} \log E P C+n E C T_{t-1}+\varepsilon_{t--}
$$

In equation $5 \mathrm{n}$ shows the speed of convergence towards equilibrium in different time period or $\mathrm{ECT}_{\mathrm{t}-\mathrm{i}}$ is the error correction term that estimate from the short term model. $\mathrm{ECT}_{\mathrm{t}-\mathrm{i}}$ must be negative and significant.

\section{EMPIRICAL FINDINGS:}

Table 1. Descriptive statistic

\begin{tabular}{lllllll}
\hline Variables & GDP & HEC & NEC & FFUL & CO $_{2}$ & EPC \\
\hline Mean & 853.269 & 39.191 & 2.104 & 55.302 & 0.730 & 335.962 \\
Median & 832.698 & 34.311 & 1.680 & 57.873 & 0.741 & 357.928 \\
Maximum & 1178.79 & 58.638 & 5.536 & 63.059 & 0.991 & 486.791 \\
Minimum & 556.310 & 25.242 & 0.013 & 40.316 & 0.410 & 9.523 \\
Skewness & 0.123 & 0.593 & 0.687 & -0.864 & -0.253 & -0.682 \\
Kurtosis & 1.961 & 1.860 & 2.305 & 2.485 & 1.809 & 2.685 \\
Observations & 37 & 37 & 37 & 37 & 37 & 37 \\
\hline
\end{tabular}

Table 1 shows that the GDPPC, HEC, NEC, FFUL, $\mathrm{CO}_{2}$, and EPC have the positive mean value of $853.268 \%$ of GDP, 39.191\% hydroelectricity use, $2.104 \%$ nuclear energy use, $55.302 \%$ fossil fuel consumption, 0.730 metrics per capita $\mathrm{CO}_{2}$ emission and $335.962 \%$ electric power consumption correspondingly. These statistics are essential for the selected variables to check the trend analysis of a country. Fig. 1 shows the data lots at a level for ready reference. 
GDP

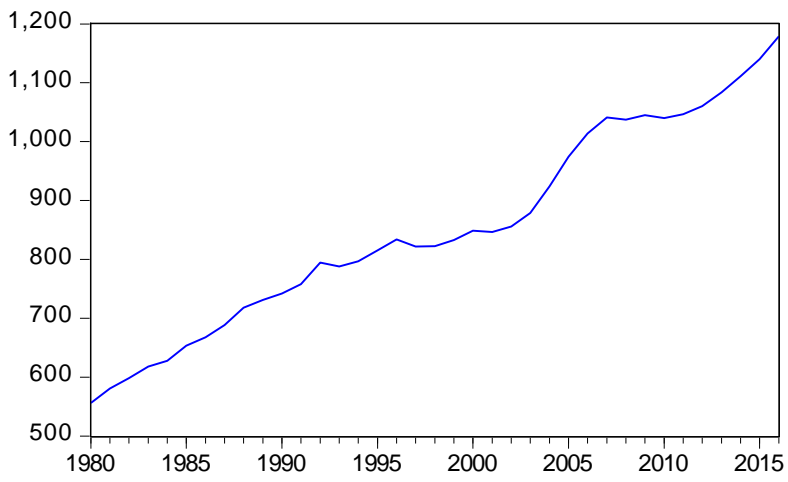

NEC

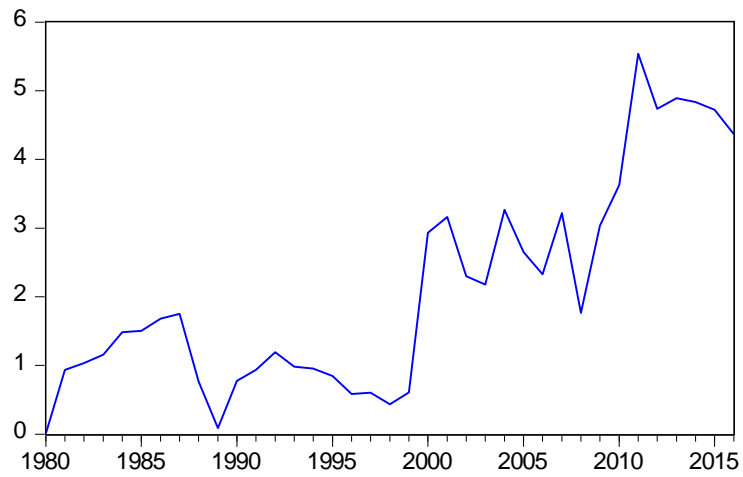

$\mathrm{CO} 2$

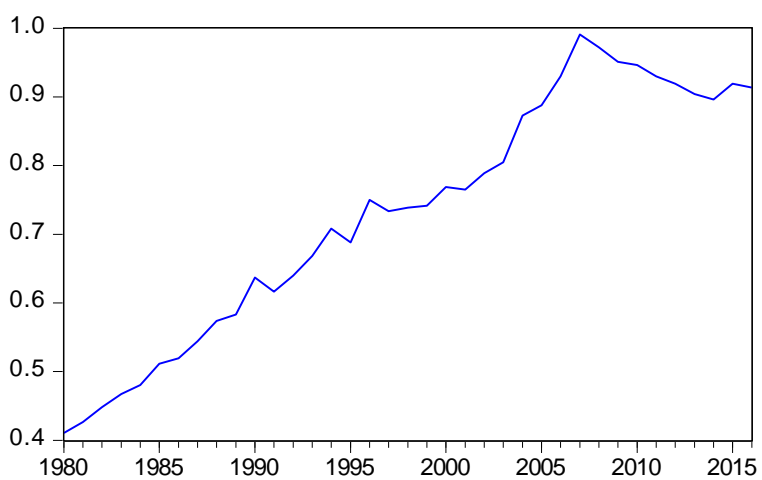

HEC

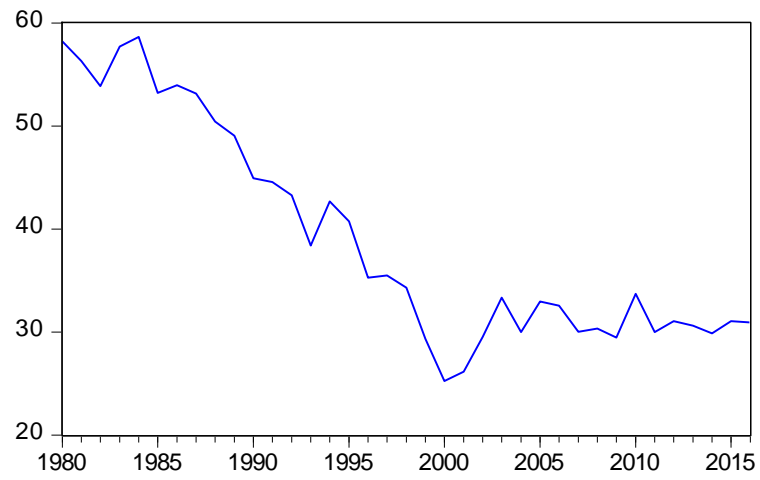

EPC

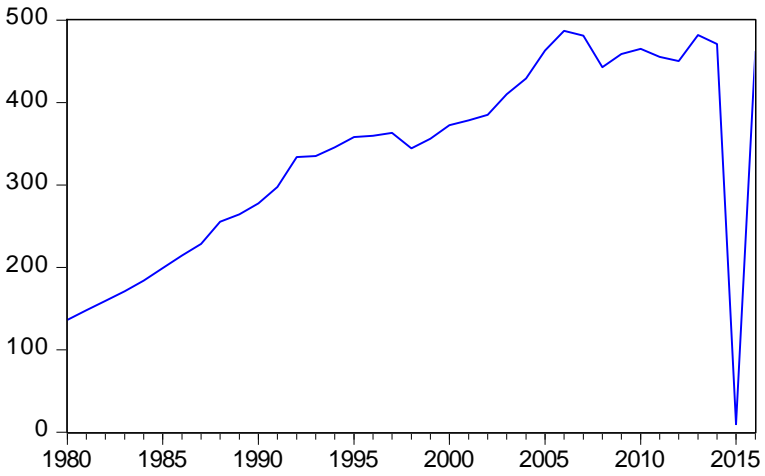

FFUL

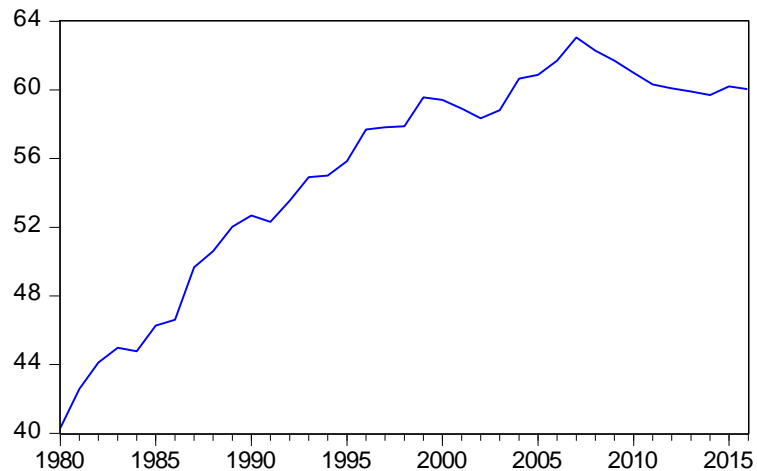

Fig. 1. Level Data Plots

Table 2. Unit root test

\begin{tabular}{lllll}
\hline \multirow{2}{*}{ Variables } & \multicolumn{2}{c}{ Level } & \multicolumn{1}{c}{$\mathbf{1}^{\text {st }}$ difference } \\
\cline { 2 - 5 } & Constant & Constant and trend & Constant & Constant and trend \\
\hline \multirow{2}{*}{ GDP } & 0.373 & -2.479 & -3.344 & -3.347 \\
& $(0.978)$ & $(0.335)$ & $(0.075)$ & $(0.020)$ \\
\multirow{2}{*}{$\mathrm{HEC}$} & -1.666 & -1.383 & -6.699 & -6.871 \\
& $(0.439)$ & $(0.848)$ & $(0.000)$ & $(0.000)$ \\
$\mathrm{NEC}$ & -1.429 & -2.622 & -6.768 & -6.696 \\
& $(0.557)$ & $(0.273)$ & $(0.000)$ & $(0.000)$ \\
$\mathrm{CO}_{2}$ & -1.831 & -0.779 & -6.117 & -6.613 \\
& $(0.359)$ & $(0.958)$ & $(0.000)$ & $(0.000)$ \\
\hline
\end{tabular}

Note: Numbers in the bracket shows the probability value. 
Table 2 shows the result of the unit root test and these results indicate that EPC and FFUL are non-stationary at the level having intercept. While GDP per capita is non-stationary at the first difference having trend and intercept, while $\mathrm{HEC}, \mathrm{NEC}$, and $\mathrm{CO}_{2}$ are nonstationary at the first difference having both intercept and intercept and trend. ADF test shows the mixed result that some variables are non-stationary at a level and some are non-stationary at first difference.

Table 3. Short run results (Dependent variable is GDP per capita)

\begin{tabular}{|c|c|c|c|c|}
\hline Variables & Co-efficient & Std- error & t-stat & probability \\
\hline$\triangle \mathrm{GDP}(-1)$ & 1.806 & 0.579 & 3.117 & $0.026^{* *}$ \\
\hline$\triangle \mathrm{GDP}(-2)$ & 1.125 & 0.673 & 1.670 & 0.155 \\
\hline$\triangle \mathrm{GDP}(-3)$ & 1.769 & 0.361 & 4.891 & $0.004^{* *}$ \\
\hline$\triangle F F U L)$ & -7.474 & 0.326 & -4.517 & $0.006^{* *}$ \\
\hline$\triangle F F U L(-1)$ & -0.393 & 0.320 & -1.227 & 0.274 \\
\hline$\triangle \mathrm{FFUL}(-2)$ & 0.818 & 0.442 & 1.847 & 0.123 \\
\hline$\left.\Delta \mathrm{CO}_{2}\right)$ & -0.545 & 0.211 & -2.580 & $0.049^{* *}$ \\
\hline$\triangle \mathrm{CO}_{2}(-1)$ & -0.739 & 0.145 & -5.095 & $0.003^{* *}$ \\
\hline$\triangle \mathrm{CO}_{2}(-2)$ & -0.090 & 0.133 & -0.683 & 0.524 \\
\hline$\triangle N E C$ & 0.016 & 0.003 & 4.971 & $0.004^{* *}$ \\
\hline$\triangle N E C(-1)$ & -0.012 & 0.002 & -4.794 & $0.004^{* *}$ \\
\hline$\triangle N E C(-2)$ & 0.004 & 0.003 & 1.264 & 0.261 \\
\hline$\triangle N E C(-3)$ & -0.014 & 0.003 & -4.374 & $0.007^{* *}$ \\
\hline$\triangle \mathrm{EPC}$ & 0.002 & 0.009 & 0.276 & 0.793 \\
\hline$\triangle \mathrm{EPC}(-1)$ & -0.736 & 0.015 & -47.732 & $0.000^{* *}$ \\
\hline$\triangle \mathrm{EPC}(-2)$ & -0.155 & 0.184 & -0.842 & 0.437 \\
\hline$\triangle E P C(-3)$ & -0.261 & 0.165 & -1.580 & 0.174 \\
\hline$\triangle \mathrm{HEC}$ & -0.222 & 0.053 & -4.160 & $0.008^{* *}$ \\
\hline$\triangle \mathrm{HEC}(-1)$ & 0.172 & 0.072 & 2.383 & $0.062^{*}$ \\
\hline$\triangle \mathrm{HEC}(-2)$ & -0.277 & 0.059 & -4.653 & $0.005^{* *}$ \\
\hline$\triangle \mathrm{HEC}(-3)$ & 0.195 & 0.107 & 1.815 & 0.129 \\
\hline ECM & -2.406 & 0.621 & -3.873 & $0.011^{* *}$ \\
\hline
\end{tabular}

Note: **, *shows the $5 \%, 10 \%$ level of significance.

Table 3 shows the short term relationship among the variables. The results indicate that the negative and significant connection between fossil fuel and GDP per capita which indicates that if $1 \%$ increases in fossil fuel would result in $1.474 \%$ reduction in the GDP per capita, hence confirming the pollution heaven hypothesis. These results are in line with Kasman and Duman (2015) suggesting the fossil fuel plays a vital role in increasing the emission of hazardous gases that results in a increase in the economic growth of Pakistan. Their study reveals that fossil fuel negatively impacts the growth indicates that increase in the emission proxy the higher growth.

$\mathrm{CO}_{2}$ is negative and significantly correlated with the GDP per capita of a country which shows that the higher economic growth degrades the environment. Alshehry and Belloumi (2015) also get the bidirectional relationship between $\mathrm{CO}_{2}$ emission and economic growth in Saudi Arabia. Carbon dioxide does not affect the growth of the economy directly, but it affects the growth through the channel of reduction in environmental quality. When the growth of the economy increases it increases the 
industries that emit the gases which would result in a reduction in the environmental quality. This outcome is also supported by Hanif et al. (2019).

The result of alternative nuclear energy consumption is positive and significantly related to Pakistan's economic growth in the short run. As $1 \%$ increase in alternative nuclear energy consumption, would increase the $0.016 \%$ growth of the economy. Apergis et al. (2010) also suggest that alternative nuclear energy consumption help promote the growth of developing countries like Pakistan. The results also suggest that nuclear energy consumption is a clean way to produce energy that helps to save and clean the environment through emission.

Clean energy of electric power consumption is negatively and significantly correlated with the economic growth of a country at its initial lag. As 1\% rise in the EPC in Pakistan reduces the $0.736 \%$ GDP per capita. This negative result shows the weak institutional framework of electricity production. The result of EPC is supported by the study of Wesseh and Zoumara (2012) suggested that more resources are required in Nigeria to produce electric power that must help promote the GDP.

Hydroelectricity production is also negative and significant correlated with Pakistan economic growth at its second lag, its role is negative due to the water crises and nonavailability of dams, so the ratio of hydroelectricity is very low and on the other hand demand for energy is high and supply is very low. In the past few years, Pakistan's economy faces energy crises that why hydroelectricity never play is positive part to increase the GDP per capita. The result is linked with the previous study of Awan and Khan (2014) due to the energy crisis the Pakistan economy effect very badly. This energy crisis is rising due to the increase in the price of hydro resources and deficiency of proper planning to fulfill the rising demand for energy.

The error correction model coefficient is negative, significant, and greater than one. The value of ECM coefficient is 2.406 shows the speed of convergence towards the equilibrium in the short run. If there is an external shock in the economy, then the system will reverse towards the equilibrium at the adjustment rate of $24 \%$ per annual.

Table 4. Bound testing ( $\mathrm{H}_{0}$ : No long-run relationship)

\begin{tabular}{llll}
\hline Test statistics & \multicolumn{1}{c}{ Value } & $\mathrm{K}$ \\
\hline F-statistics & 8.013** & 5 \\
\hline \multicolumn{4}{c}{ Critical value of bound testing: } \\
\hline Significance & O bound & 1 bound \\
\hline $10 \%$ & 2.26 & 3.35 & \\
$5 \%$ & 2.62 & 3.79 & \\
$2.5 \%$ & 2.96 & 4.18 & \\
$1 \%$ & 3.41 & 4.68 & \\
\hline
\end{tabular}

Note: Long run association exists as F-statistic is greater than the 7 bound and significance level is $1 \%$. ${ }^{* *}$ shows significant at $1 \%$

Table 5 indicates the outcome of bound testing. The bound test result shows that the study achieves the long-run correlation among the variables by employing the ARDL approach advanced by Pesaran et al. (2001). The value of the F-statistic is 8.013 that is larger than the 1 bound 4.68 at a significance level of 1\%; it shows the robust long-run 
association among the GDP per capita and the alternative clean energy use in Pakistan. Hence $\mathrm{H}_{0}$ is rejected that is no long-run association between the variables and accept $\mathrm{H}_{1}$.

Table 5. Long run results

\begin{tabular}{lllll}
\hline Variables & Co-efficient & Std. error & t-statistics & probability \\
\hline FFUL & -0.417 & 0.272 & -1.532 & 0.185 \\
$\mathrm{CO}_{2}$ & 0.027 & 0.073 & 0.379 & 0.720 \\
$\mathrm{NEC}$ & 0.015 & 0.002 & 6.873 & $0.001^{* *}$ \\
EPC & 0.480 & 0.095 & 5.030 & $0.004^{* *}$ \\
$\mathrm{HEC}$ & -0.051 & 0.078 & -0.656 & 0.540 \\
$\mathrm{C}$ & 2.469 & 0.407 & 6.059 & $0.001^{* * *}$ \\
\hline
\end{tabular}

Note: ${ }^{* *}{ }^{* * *}$ shows the significance level is $5 \%$ and $10 \%$ respectively

Table 5 shows the long-run correlation between the variables. And the result illustrations that nuclear energy consumption is positively and significantly correlated with the GDP per capita in the long run. It indicates that long-run use of nuclear energy consumption stimulates the GDP per capita of Pakistan's economy. The result of Apergis and Payne (2009) also cooperate that nuclear energy consumption boosts the growth of a country. When alternative energy consumption increases it would promote the growth of the Pakistan economy because the cost of producing energy through this process is low, so the cost of production unit reduces, and they can increase their output that would result in increase in the growth of the economy.

Similarly, electric power consumption is also significant and positive. This indicates that the in the long the use of electric power consumption saves the environment from degradation. Renewable energy consumption also plays its positive role to boost the growth of Latin American countries in long run (Al-Mulali et al., 2013). So, it would also be helpful if the Pakistan government increases the renewable project while producing electricity it will not only promote the GDP per capita but also cleans the environment from the emission of hazardous gases.

\subsection{CONCLUSION:}

This study is based to assess the role of energy consumption, $\mathrm{CO}_{2}$ emission, and economic growth of Pakistan's economy. The study concludes that fossil fuel energy consumption and $\mathrm{CO}_{2}$ emission adversely affect the capita growth in Pakistan. However alternative nuclear energy consumption plays its potential role to boost economic growth in the short as well as in the long run. These findings are in line with Mansoor and Sultana (2018) and Naz et al. (2019) that renewable energy is the key source of energy consumption for sustainable growth and development. In the short run, electric power consumption contributes less to GDP per capita but rather plays a significant role to boost the economic growth of the country in the long run. Due to the energy crisis, hydroelectric consumption never contributes to an increase in the GDP per capita in Pakistan. It is quite evident that renewable energy consumption plays a vital role in economic development via the channel of reduction in $\mathrm{CO}_{2}$ emissions and fossil fuel combustion across the country. The importance of nuclear energy consumption in renewable energy sources is 
widely visible in the energy resource framework where high environmental pollutants might be mitigated by the inclusion of nuclear energy consumption in the energy mix.

\subsection{POLICY IMPLICATIONS:}

The study concludes that the economy must focus to increase the consumption of renewable energy sources because non-renewable sources like fossil fuel would result in the emission of $\mathrm{CO}_{2}$ that reduce the environment quality and it affects the ecosystem and these emissions of harmful gases also deplete the ozone layer and increase the greenhouse gas emissions. In the long run, sustainable development is necessary to reduce greenhouse gas emissions and climate changes. The economy must focus on renewable energy consumption to fulfill its energy need. To save the environment government must adopt policies that not only fulfill the energy need of the masses but also protect the environment. Global warming is one of the prominent impacts of the greenhouse gases that would result in to increase in the earth's temperature by deforestation and the use of fossil fuel. The focus must be on the green economy. Green Pakistan's agenda of the current government is one of the practical implications which is in line with the outcome of this study. Plantation of trees would help to reduce $\mathrm{CO}_{2}$ emission. Policies that are related to the renewable sources are helpful because it helps to preserve the natural environment and also became a very cheapest source to produced energy.

\section{References:}

Al-Maamary, H. M., Kazem, H. A., \& Chaichan, M. T. (2017). The impact of oil price fluctuations on common renewable energies in GCC countries. Renewable and Sustainable Energy Reviews, 75, 989-1007.

Al-mulali, U., Fereidouni, H. G., \& Lee, J. Y. (2014). Electricity consumption from renewable and non-renewable sources and economic growth: Evidence from Latin American countries. Renewable and Sustainable Energy Reviews, 30, $290-298$.

Alshehry, A. S., \& Belloumi, M. (2015). Energy consumption, carbon dioxide emissions and economic growth: The case of Saudi Arabia. Renewable and Sustainable Energy Reviews, 47, 237-247.

Apergis, N., \& Payne, J. E. (2009). Energy consumption and economic growth: evidence from the Commonwealth of Independent States. Energy Economics, 37(5), 641647.

Apergis, N., Payne, J. E., Menyah, K., \& Wolde-Rufael, Y. (2010). On the causal dynamics between emissions, nuclear energy, renewable energy, and economic growth. Ecological Economics, 69(11), 2255-2260.

Apergis, N., Payne, J. E., Menyah, K., \& Wolde-Rufael, Y. (2010). On the causal dynamics between emissions, nuclear energy, renewable energy, and economic growth. Ecological Economics, 69(11), 2255-2260.

Archived copy Archived form the Orginal on Marchz, 2009 Retrieved April 2, 2008 
Awan, A. B., \& Khan, Z. A. (2014). Recent progress in renewable energy-Remedy of energy crisis in Pakistan. Renewable and Sustainable Energy Reviews, 33, 236-253.

Bekhet, H. A., Matar, A., \& Yasmin, T. (2017). $\mathrm{CO}_{2}$ emissions, energy consumption, economic growth, and financial development in GCC countries: Dynamic simultaneous equation models. Renewable and Sustainable Energy Reviews, 70, 117-132.

Bloch, H., Rafiq, S., \& Salim, R. (2015). Economic growth with coal, oil and renewable energy consumption in China: Prospects for fuel substitution. Economic Modelling, 44, 104-115.

Cheng, B., Dai, H., Wang, P., Zhao, D., \& Masui, T. (2015). Impacts of carbon trading scheme on air pollutant emissions in Guangdong Province of China. Energy for sustainable development, 27, 174-185.

Chontanawat, J. (2020). Relationship between energy consumption, $\mathrm{CO}_{2}$ emission and economic growth in ASEAN: Cointegration and causality model. Energy Reports, $6,660-665$.

Dabachi, U. M., Mahmood, S., Ahmad, A. U., Ismail, S., Farouq, I. S., Jakada, A. H., \& Kabiru, K. (2020). Energy Consumption, Energy Price, Energy Intensity Environmental Degradation, and Economic Growth Nexus in African OPEC Countries: Evidence from Simultaneous Equations Models. Journal of Environmental Treatment Techniques, 8(1), 403-409.

Dai, H., Xie, X., Xie, Y., Liu, J., \& Masui, T. (2016). Green growth: The economic impacts of large-scale renewable energy development in China. Applied energy, 162, 435449.

Estimate based on sources and methods described in "The changing wealth of nations Measuring Sustainable Development in the New Millennium" World Bank 2011.

Gralla, F., Abson, D. J., Møller, A. P., Lang, D. J., \& von Wehrden, H. (2017). Energy transitions and national development indicators: A global review of nuclear energy production. Renewable and Sustainable Energy Reviews, 70, 1251-1265.

Hanif, I., Raza, S. M. F., Gago-de-Santos, P., \& Abbas, Q. (2019). Fossil fuels, foreign direct investment, and economic growth have triggered $\mathrm{CO}_{2}$ emissions in emerging Asian economies: some empirical evidence. Energy, 171, 493-501.

Hydropower in Pakistan - World Energy Council 2017 https://www.worldenergy.org/data/resources/country/pakistan/hydropower/

Inglesi-Lotz, R. (2016). The impact of renewable energy consumption to economic growth: A panel data application. Energy Economics, 53, 58-63.

Kasman, A., \& Duman, Y. S. (2015). $\mathrm{CO}_{2}$ emissions, economic growth, energy consumption, trade and urbanization in new EU member and candidate countries: a panel data analysis. Economic Modelling, 44, 97-103.

Kazmi, S, T, H., Rehman, I., \& Nasrullah, A. (2016). China's Journey in Renewable Energy and Its Potential Spillover Effects Through The CPEC In Pakistan. 
Khan, M. M., Zaman, K., Irfan, D., Awan, U., Ali, G., Kyophilavong, P., Naseem, I. (2016). Triangular relationship among energy consumption, air pollution and water resources in Pakistan. Journal of Cleaner Production, 172, 1375-1385,

Kugelman, M. (2015). Pakistan's Interminable Energy Crisis: is there any way out? The Wilson Center, Washington, DC.

Lee, C. C., \& Lee, J. D. (2009). Income and $\mathrm{CO}_{2}$ emissions: evidence from panel unit root and cointegration tests. Energy policy, 37(2), 413-423.

Mahmood, N., Wang, Z., \& Zhang, B. (2020). The role of nuclear energy in the correction of environmental pollution: Evidence from Pakistan. Nuclear Engineering and Technology, 52(6), 1327-1333.

Mansoor, A., \& Sultana, B. (2018). Impact of population, GDP and energy consumption on carbon emissions: evidence from Pakistan using an analytic tool IPAT. Asian Journal of Economics and Empirical Research, 5(2), 183-190.

Naz, S., Sultan, R., Zaman, K., Aldakhil, A. M., Nassani, A. A., \& Abro, M. M. Q. (2019). Moderating and mediating role of renewable energy consumption, FDI inflows, and economic growth on carbon dioxide emissions: evidence from robust least square estimator. Environmental Science and Pollution Research, 26(3), 28062819.

Nkoro, E., \& Uko, A. K. (2016). Autoregressive Distributed Lag (ARDL) cointegration technique: application and interpretation. Journal of Statistical and Econometric Methods, 5(4), 63-91. Online available at: http://pide.org.pk/psde/pdf/AGM32/papers/China\%20Journey\%20in\%20Renewa ble.pdf (accessed on 24 $4^{\text {th }}$ April, 2018).

Pesaran, M. H., Shin, Y., \& Smith, R. J. (2001). Bounds testing approaches to the analysis of level relationships. Journal of applied econometrics, 16(3), 289-326.

Plans for New Reactors Worldwide; world nuclear association (Updated January 2018)

Shahbaz, M., Sarwar, S., Chen, W., \& Malik, M. N. (2017). Dynamics of electricity consumption, oil price and economic growth: Global perspective. Energy Policy, 108, 256-270.

Sharif, A., Mishra, S., Sinha, A., Jiao, Z., Shahbaz, M., \& Afshan, S. (2020). The renewable energy consumption-environmental degradation nexus in Top-10 polluted countries: Fresh insights from quantile-on-quantile regression approach. Renewable Energy, 150, 670-690.

sianics Agro-Dev. International (Pvt) Ltd. (2000). Tarbela Dam and related aspects of the Indus River Basin, Pakistan (PDF) (Report). Cape Town: World Commission on Dams. Archived from the original (PDF) on 2010-06-13. Retrieved 2010-10-28.

Stern, D. I. (2004). Economic growth and energy. Encyclopedia of Energy, 2(00147), 35-51.

Tang, C. F., \& Tan, B. W. (2015). The impact of energy consumption, income and foreign direct investment on carbon dioxide emissions in Vietnam. Energy, 79, 447-454. 
Tang, C. F., \& Tan, B. W. (2015). The impact of energy consumption, income and foreign direct investment on carbon dioxide emissions in Vietnam. Energy, 79, 447-454.

Tang, C. F., Tan, B. W., \& Ozturk, I. (2016). Energy consumption and economic growth in Vietnam. Renewable and Sustainable Energy Reviews, 54, 1506-1514.

Usman, A., Ullah, S., Ozturk, I., Chishti, M. Z., \& Zafar, S. M. (2020). Analysis of asymmetries in the nexus among clean energy and environmental quality in Pakistan. Environmental Science and Pollution Research, 7-72.

Wesseh Jr, P. K., \& Zoumara, B. (2012). Causal independence between energy consumption and economic growth in Liberia: Evidence from a non-parametric bootstrapped causality test. Energy Policy, 50, 518-527.

Wolde-Rufael, Y., \& Menyah, K. (2010). Nuclear energy consumption and economic growth in nine developed countries. Energy Economics, 32(3), 550-556.

World Development Indicator (2016). WDI, 2016, World Bank, Washington D.C.

World energy outlook, (2017) international energy agency https://www.iea.org/weo2017/

Xie, Y., Dai, H., \& Dong, H. (2018). Impacts of SO2 taxations and renewable energy development on $\mathrm{CO}_{2}, \mathrm{NOx}$ and $\mathrm{SO} 2$ emissions in Jing-Jin-Ji region. Journal of Cleaner Production, 171, 1386-1395.

Zaman, K. (2020). Does Materials Technology Pay its Carbon Price?. Journal of Economic Info, 7(2), 751-752.

Zaman, K., Abdullah, I., \& Ali, M. (2017). Decomposing the linkages between energy consumption, air pollution, climate change, and natural resource depletion in Pakistan. Environmental Progress \& Sustainable Energy, 36(2), 638-648. 